\title{
A good business or a risky business: Health, safety and quality of life for women small- scale miners in PNG
}

Danellie Lynas

Alluvial and small-scale mining operations in Papua New Guinea (PNG) are collectively referred to as small-scale mining (SSM). Artisanal and small-scale mining (ASM), as this practice is most often referred to in the literature, describes an economically significant and growing area in more than 80 mineral-rich developing countries, and producing approximately 15-20 per cent of global minerals and metals (Jennings 2003; Buxton 2013). A 1999 International Labour Organization (ILO) estimate (Jennings 1999) places the number of people directly and indirectly dependent on ASM at 100 million. However, the worldwide mineral boom of the last decade, coupled with continued diversification of rural livelihoods suggests that this number is steadily increasing (World Health Organization (WHO) 2013). With no universal definition of ASM, it is usually distinguished as low-technology, labour-intensive mineral extraction and processing found across the developing world, and distinguished from industrial mining by low rates of production, lack of long-term planning, inadequate equipment and poor safety, health and environment conditions (Hilson 2002; Hilson and McQuilken 2014). 
PNG alluvial gold-mining dates back to the late 1880s, when during the colonial era the industry was dominated by Europeans who employed PNG nationals (Hancock 1994; Susapu and Crispin 2001; Lole 2005). By the late 1960s, most Europeans had abandoned their leases and growing numbers of nationals commenced their own operations. Since independence in 1975, ASM has rapidly increased in scale, underpinning economic activity in much of rural and remote PNG (Moretti 2007; Papua New Guinea Mine Watch 2015b). While many miners are satisfied with non-mechanised mining to sustain their livelihood, others are looking for opportunities to form joint-venture operations that may provide necessary capital and skills to increase production levels and improve livelihoods (Crispin 2006; Moretti 2007). Unlike other parts of the world, PNG recognises SSM as a legal contributor to the national economy, with estimates of up to 90 per cent of alluvial gold production being extracted by rural-based miners using sluice boxes and panning dishes, with some mechanised operations using predominantly portable dredges, water pumps and excavators (Crispin 2003; Javia and Siop 2010). Mercury is widely used in PNG, with between 60 and 90 per cent of operations reportedly using it in capturing and amalgamating the gold (Crispin 2006; Leonhard 2015). Alluvial and small-scale mining is administered by the Mineral Resources Authority (MRA), and governed by the Mining Act 1992 and the Mining (Safety) Act \& Regulations 2007, which apply equally to alluvial and hard-rock mining. Current legislation recognises customary landowners, allowing non-mechanised alluvial mining on their land without the need to obtain a registered lease, while large-scale mining leases are required to have at least 51 per cent national ownership. While alluvial and placer gold is found almost everywhere in PNG, the remoteness of many of these sites makes it difficult both financially and technically to locate mechanised equipment on site. As a result, simple, non-mechanised techniques remain the most widely used.

Research indicates that most of the SSM population lacks the financial and educational capacity required to undertake fully mechanised or largerscale mining operations. SSM is most often undertaken in family units of two to five people, with estimates indicating that this group comprises almost 99 per cent of total SSM operations (Lole 2005; Crispin 2006; Moramo 2015). Similar to other mineral-rich developing countries, alluvial mining in PNG is extensively practised as an alternative economic seasonal activity where, in times of economic stress, many miners live a subsistence lifestyle driven by commodity prices and basic needs, and switch between fishing and market gardening, and mining. Their level of 
involvement is often governed by festivities and family expenses, such as school and medical fees. Reports indicate that SSM is usually undertaken at will, without systematic planning of operations, employs rudimentary equipment and involves high labour intensity, with an average weekly gold recovery of approximately 2.5 grams (Moramo 2015). Additionally, PNG miners often undertake multiple income-generating activities at the same time (Lole 2005; Javia and Siop 2010; Moramo 2015).

While representing an important livelihood strategy for rural households, SSM generally encompasses a significant amount of risk and vulnerability, including problems with government licensing schemes, disputes over land ownership, environmental degradation and health and safety issues (Javia and Siop 2010; Lole 2005; Leonhard 2015; Moramo 2015). Recent press releases quote Morobe Province Governor Kasiga Kelly Naru as confirming 'alluvial mining is the source that measures the income and livelihoods of ordinary landowners involved in the activity', and for most miners it is a survival strategy for remote and rural communities. Morobe is one of the oldest mining areas of PNG. For miners seeking greater financial outcomes by entering into joint venture partnerships, acquiring a mining lease is a long process. The applicant must meet regulatory requirements by submitting detailed survey reports, development plans, compensation plans, environmental plans and financial capacity reports to the MRA for approval. In another press release, the MRA's managing director, Philip Samar, has been quoted as saying, 'Alluvial mining is a sleeping giant that has captured Mineral Resource Authority's (MRA) attention and the goal is to encourage and promote alluvial mining to meet Governments' medium and long term development plans because the bigger mining companies could not deliver alone'; further commenting, 'by 2020-30, alluvial mining would double the revenue for the Government coffers', and that as the government mining regulator, the MRA would design best practices to protect it (Papua New Guinea Mine Watch 2015a).

\section{Health and safety}

Definitions of occupational health and safety vary across authors. However, as defined by the WHO, 'occupational health deals with all aspects of health and safety in the workplace and has a strong focus on primary prevention of hazards' (WHO n.d.-b), with health defined as 'a state of complete physical, mental and social well-being and not merely 
the absence of disease or infirmity' (WHO n.d.-a). Across the developed world, the most effective health and safety management programs are based on strong risk management principles, underpinned by knowledge that provides the ability to assess and manage work-related hazards. While aspects of ASM health and safety have captured international attention and concern, primarily due to the use of mercury in gold processing, a lack of information exists on the other health and safety risks impacting these miners. An extensive literature review reveals that most health and safety issues faced by ASM workers are attributed to the illegal nature of the operations, in combination with competing socio-economic demands, lack of expertise and training in safety measures and inadequate equipment (Jennings 1999). Basic record-keeping and data collection remains minimal in ASM administration, largely due to miner illiteracy, workforce itinerancy and lack of human resource capacity within the regulatory bodies overseeing ASM operations (Minerals Commission Ghana 2014; Minerals Resources Authority 2015). Although widespread illegality within ASM generally leads to under-reporting of accidents and deaths, Jennings (1999) reports indicate that non-fatal deaths in ASM are up to six to seven times that of formal large-scale operations (Hinton et al. 2003). A study by Hentschel et al. (2002) found the most common occupational health and safety deficiencies in small-scale mining to be lack of awareness of the risks in mining, coupled with lack of education and training.

It is reported that many underground ASM accidents result from poor understanding of mine shaft ventilation practices, with asphyxiation frequently occurring as miners either work in shafts while compressors are operational or miscalculate and re-enter shafts before adequate ventilation and air quality have been re-established, post blasting (Gratz 2003). Reports from South America and sub-Sahara Africa indicate that most accidents among ASM operators are caused by rock falls and subsidence, use of poorly maintained equipment and poor safety practices, including non-compliance with wearing proper protective equipment. Inadequate understanding of mining and ventilation practices have been identified as the major causes of fatality with suffocation, uncontrolled explosions and being trapped or buried listed as the top three incidents leading to miner deaths. Other identified health issues include dust, food quality, extreme heat in the pits and shafts, mercury vapour inhalation, waterborne diseases, water-related problems, such as falls when the site is slippery, red eyes caused by muddy water, and body pains from lifting and 
carrying heavy loads. Concerns also include pit instability and collapse, load falls resulting in injury or death, rising water from the underground water table and flooding of pits, shafts and ghettos (Tschakert 2009; Lopez-Trueba 2014). A 2009 presentation by CEO Toni Aubynn to the Ghana Chamber of Mines listed health and safety as one of the four key challenges faced in regulatory management of ASM in Ghana.

Communities that have ASM operations nearby are in turn exposed to environmental safety and health hazards due to contamination of the larger environment through water run-off, air contamination, ground contamination, landslides and subsidence, as SSM operators rarely attempt land rehabilitation post mining operations (Hilson 2002; Hinton et al. 2003; Veiga and Baker 2004; Moretti 2007). Water contamination due to improper waste disposal, erosion in mining sites and mercury and cyanide poisoning have been linked to increased rates of cancer and skin lesions, while contamination in water systems also disrupts the aquatic ecosystem, eventually affecting humans (Veiga and Baker 2004; Moretti 2007).

Mercury and cyanide are the two most significant chemicals widely used in gold processing across most countries where ASM is practised. Mercury is poisonous to humans and other living organisms, and the effect is intensified through bioaccumulation. While the most significant side effect on the human body is neurotoxicity, mercury also crosses the placenta, causing foetal abnormalities, and it also affects the respiratory tract, digestive system, skin and eyes. The effect of mercury on the human body and the environment has been extensively researched and reported, and elimination of mercury from gold processing remains the focus of many funded programs, such as the World Bank, International Council for Mining and Metals (ICMM), Fairtrade Foundation and Alliance for Responsible Mining, Blacksmith Institute and, most recently, the Minamata Convention on Mercury Reduction. Many authors argue that the health effects of environmental pollution are disproportionately felt by women miners because of their role as primary carers responsible for the health of their families, and as agriculturalists and miners. Women's reproductive role increases their vulnerability to mercury and other heavy metals in water and food supplies, with mercury known to severely affect foetal development (Hinton et al. 2003; Lahiri-Dutt 2006; Van Hoecke 2006; Hayes 2008; Simatauw 2009; Jenkins 2014). 


\section{Women in ASM}

Men and women are differently involved in, and differently affected by, mining practices, cultural practices and legislative practices, and often their role is dependent on the mineral commodity mined. Estimates indicate that the proportion of women engaged worldwide in ASM is approximately 30 per cent (Hilson 2002; Hinton et al. 2003). In Asian countries it is reported that women make up close to 50 per cent of miners, and in parts of Africa, anywhere between 40 and 100 per cent of the workforce are women (Jennings 1999; Hilson 2002; Lahiri-Dutt 2008). Current estimates indicate that over 100,000 persons are involved in alluvial mining across PNG, of which approximately 30 per cent are women (personal communication, A.B. Comparativo, Manager SmallScale Mining Training Centre, Wau, PNG (SSMTC), 23 October 2015).

Traditionally, women are associated with the labour-intensive tasks of transporting and processing, involving high levels of manual activity to extract mineral remnants by hand from tailings, and panning and sluicing mud and sand to recover particles of gold, while yielding the lowest economic return (Hinton et al. 2003). Benefits from mined and processed resources frequently reside with the men, while the women often do not receive an independent wage, and earn less than their male counterparts for performing similar work. In some countries, women do own mines and mining equipment, but this is not common practice (Hentschel et al. 2002; Hilson 2002; Heemskerk 2003; Hinton et al. 2003; Van Hoecke 2006). Typically, women encounter difficulties obtaining development assistance, including access to bank credit, technical knowledge and skills development (Hilson 2002; Hinton et al. 2003; Eftimie et al. 2012). This poses significant challenges for women who are household heads, as mining is often their only economic option. A number of studies indicate that money generated by women miners contributes more directly to household well-being than that of the men, with women's income providing for food, education, medical expenses and replenishing agricultural cropping needs, while men's income is often spent on gambling, prostitution and alcohol (Jennings 1999; Krimbu 2005; Javia and Siop 2010). While women's mining contributions are often in ancillary roles such as food vendors, sex workers and other service providers, these roles are performed in addition to their domestic responsibilities, often making their contribution 'less visible', and therefore less recognised and valued (Lahiri-Dutt 2006, 2012). A comprehensive 
literature critique by Jenkins (2014) provides valuable insight into the ways women are affected by ASM mining activities, with the author highlighting a lack of in-depth analysis of women's diverse experiences as mine workers across a number of parameters, including gender impacts of mining, changing gender dynamics and gender inequalities in mining communities.

Access to education is critical to empowering women to derive greater benefits from ASM. However, in many countries, girls are still discriminated against in terms of education, mainly due to social and cultural barriers, and family expectations that they will assume domestic responsibilities. Additionally, cultural taboos and superstitions often exclude women from working in mines due to beliefs that they will bring bad luck by attracting bad spirits or offending the gold god (Hinton et al. 2003; Moretti 2006). While women are critical to the stability and cohesiveness of their communities and often act as change facilitators, they are often excluded from the decision-making process based on gender (Hinton et al. 2003). Lahiri-Dutt (2012) emphasised the importance of 'asking what mining really means to [women in] poorer communities'. In communities where women feel they do have the ability to influence decisions, they often lack access to knowledge that will better equip them to act in an informed capacity.

\section{Current occupational health and safety issues in PNG}

Small-scale mines in PNG experience many of the global health and safety issues. Trainers from the MRA-managed SSMTC located in Wau in Morobe Province, the oldest mining area of PNG, have identified the low education level of the miners, particularly in relation to technical knowledge and mining expertise, lack of knowledge of the dangers associated with mining operations, the rudimentary nature of the equipment used, low production outputs, the propensity of the miners to spend all that they make and not save and the seasonality of their operations as challenges to developing effective health and safety practices. Additional significant management challenges include the location and accessibility of operations, cultural practices and social beliefs, the technical and economic environments the mines operate in, including lack of access to available credit facilities, fair access to market and fair 
price for the gold they mine. Trainers indicate that records show at least five to six reported deaths per year in SSM largely due to unsafe work practices.

In an account of women alluvial and small-scale miners in PNG, Crispin highlighted the vital source of income that mining provides for many rural-based communities, arguing that 'access for women to the economic benefits, skills involved, and awareness of possible health and safety issues is important for community based mining to remain sustainable and to continue to contribute to economic survival and development' (2006: 256-7). Following fieldwork undertaken in the Mount Kaindi area, Moretti observed that local women 'face serious obstacles to full and equitable participation in mining' (2005: 133-4). These obstacles included cultural beliefs, land tenure practices, unequal control of household resources and gendered division of labour. In many regions of PNG, women are considered a dangerous presence on a mine site, with the belief that they can pollute the gold and anger hikoapa, the ancestral and nature spirits that guard the land and its riches (Moretti 2005).

As in many other developing countries, PNG women often take their children on-site, as there is nowhere else to leave them. Reports indicate that around 30 per cent of school-age children are working on SSM sites rather than attending school; however, extensive awareness campaigns have seen this number reduced to around 15 per cent (personal communication, A.B. Comparativo, Manager Small-Scale Mining Training Centre Wau, PNG, 23 October 2015). Girls make up the largest proportion of this number, often being kept back from school simply for gender reasons (Krimbu 2005). Child labour remains a significant issue in PNG, with many children leaving school in order to mine to support themselves and their families. Children on the site are exposed to dust, falling objects, machinery noise, heavy manual work and mercury vapour. Women and children are particularly exposed to drugs, communicable diseases such as HIV/AIDS and gender-based violence (GBV).

Typical of many SSM communities, PNG women mine on a seasonal basis, either at times of increased financial commitment such as payment of school and medical fees, or in conjunction with other seasonal incomeearning activities such as market gardening, cropping and animal rearing. Lack of community access to clean running water and sanitation facilities substantially adds to the impact and challenge of managing healthrelated issues within the communities. While many communities accept 
the situation as a normal way of living, exposure to water-borne diseases such as malaria and cholera, and continued use of unsafe and often mercury-contaminated water for cooking, drinking and washing remains detrimental to the health of the whole community.

In a thesis completed on an Andean mining community in Bolivia, Lopez-Trueba (2014) makes a distinction between specific 'health and safety risks' and the broader range of dangers, uncertainties, risks and ambiguities associated with miners' livelihoods, referring to them as 'occupational uncertainties', and indirect causes of occupational health and safety risks. Taking this broader approach allows for further exploration and understanding of the health and safety issues from the perspective that these issues are rooted in the immediate and wider socio-political and economic contexts in which the miners live and their livelihoods take place. This discussion takes up this concept and explores health and safety issues among women small-scale miners and their communities in an alluvial gold-mining province in PNG.

\section{Methodology}

Ethnographic research provided the opportunity to better understand how gender-specific health and safety concerns impact on the lives of two groups of women involved in alluvial gold-mining in PNG. Two field trips were undertaken to the Wau area where local women actively engaged in small-scale mining in their local area were interviewed. One group comprised of 16 women and the other had 12. Group and individual semi-structured interviews, direct field observation, photos and video footage were used to gain an overall picture of the health and safety issues experienced by the group. An interpreter was used for the interviews. The questions asked in the semi-structured interviews covered basic parameters such as age, education level, years spent mining, why they had started and continued mining, if they would prefer to not be mining, and if so what they would prefer to do, how much time they spent mining, and how much time on agricultural work and family responsibilities, if the lease was held in their name, and how much longer they thought they would continue with mining. Specific questions were then asked regarding health and safety issues they encountered both in relation to their mining and to their family and community responsibilities. They were also asked if they would prefer if their children did not become miners and, if so, what kind of employment they would like them to have. 


\section{Women in SSM in PNG: Reflections from the field}

We have been neglected for a long time, even our parents were neglected. It is only now we are being recognised and recently there has been some change. We need to be recognised, I have had enough of working in rivers ... if I could do something else ... or if there was machinery we could use to help us so we don't need to work so hard, I could keep going.

Cultural diversity within PNG means the status and role of women varies, with some areas being matrilineal and some patrilineal, with economic and social power differing accordingly. Women in PNG are predominantly restricted by their lack of ownership over mining land, with almost all registered mining leases, tributary agreements and customary land being held by men and transmitted patrilineally. While in practice some women do hold certain secondary rights to land and resources of their kin, these rights are mostly claimed and exercised by their spouses and male relations (Moretti 2005).

This is evident from an extract from the group interviews:

I have had no control over the lease since my husband died-others ['settlers'] have come in and we are trying to move them on. My son-inlaw and grandsons make the decisions.

With this division of ownership rights come problems of domestic violence, rape, HIV/AIDS and lack of economic equality between women and men, as well as lack of adequate opportunities to obtain equality (Crispin 2006). Some of the women in the group reported being victims of domestic violence. Recent media reports from the Porgera mine area in PNG highlight the gang rape of women while scavenging mine site tailings (Papua New Guinea Mine Watch 2015a). Women in mining regions are particularly vulnerable to socio-economic hardship, and are largely forced towards mining for the economic survival of their families. An account by Macintyre (2006) of women in Lihir Province indicated that women take on multiple roles simultaneously, leading to them being overworked and overburdened. This was supported by the evidence gathered through the field narrative:

My body is tired. I want to stop working, I will only work when we need extra money for school and medical help. (Older woman from SSM alluvial mining area in PNG) 
Traditionally, women undertake heavy manual work, and a number of the interviewed group reported back and knee pain from shovelling, lifting and carrying heavy rocks. In most SSM in PNG alluvial gold-mining, women reported working long hours bending and twisting to pan and sieve, while standing or squatting in water often contaminated by mercury. Some of the group reported back pain and internal organ pain/uterine pain, and many of the women indicated they had to continue lifting heavy and awkward equipment and loads while pregnant. Most reported that they worked while pregnant and breastfeeding, and all reported concerns about miscarriages when working while pregnant. The women also described work practices leading to musculo-skeletal, joint and abdominal pain, infected cuts that were slow to heal and abrasions and bruising from stones falling on them. On observation, many of the women had abrasions on their hands and feet and broken toenails. A typical narrative is as follows:

I work long hours in the river water, I have sores on my fingers that don't heal. Rubbing the gravel on the sluice boxes gives me a rash and blisters that take a long time to heal. I have sores on my feet from standing for a long time in the river.

Many of the women reported extreme tiredness, as their mining work is additional to their domestic responsibilities, and indicated that tiredness led them to undertake what they considered unsafe practices in order to complete their mine work to get back to their families. Typical narratives included:

My body aches. I have back pain, my joints hurt. I have back pain, and pain in my shoulders and knees from using shovels and crowbars. My hands and fingers are sore from long hours using sieves. I have sores that don't heal from handling big stones. I get headaches from working long hours in the sun. I am exhausted.

My back hurts all the time now and my insides hurt by the end of the day, I am standing in water all day, I have been doing this since I was seven years old — my body is just so tired, I don't think I can do this anymore. If there was another way to do this maybe I could keep working.

Mercury is widely used across alluvial mining activities in PNG, and all women interviewed reported concerns about mercury use and its effect on them and their families. Almost all reported symptoms attributable to exposure to mercury, and many admitted they burned mercury at home on the kitchen stove for amalgamation. It is often reported in literature that amalgamation is usually undertaken by the men; however, the women interviewed indicated that they were responsible for burning the mercury 
to amalgamate the gold they had panned during the day. Practised out of necessity rather than choice, recovered gold is amalgamated daily and sold to provide immediate money for household essentials. Many of the women reported eye problems from the mercury fumes, and many displayed physical signs of eye irritation such as redness and tears. However, most of the women indicated that they would continue the practice as it meant that at the end of the day they had money for food and other family necessities. Typical narratives included:

I know I shouldn't burn the mercury on the stove at home, but the days are long and I am bending and panning all day, I get home tired. I get up early to get my housework done and my children to school, then I travel by truck to river, it is a long way. I spend long hours lifting, shovelling and throwing stones, it's a long day and by the time I get home I am exhausted. If the day is too long I bring home the gold and do it [the amalgamation] at home so I can sell it to pay for food.

I get up at 6 am to do my housework and get my children ready for school. I then work until 3 or $4 \mathrm{pm}$ collecting concentrate. I then need to amalgamate it. Sometimes I am still on site at $6 \mathrm{pm}$. I am too tired at the end of the day so I take it home and burn it at home.

Most of the women indicated that they lived in traditional houses, often without running water or sanitation facilities, meaning that in addition to their mining work they need to carry fresh water to their houses for washing and cooking. In a vicious cycle, the mining contamination of local water bodies means additional distances need to be travelled to collect water suitable for drinking and cooking. Transport limitations add to the day, with long hours on foot or travelling in the back of a truck to their mining lease or to shopping facilities. Some families reported living on the riverbank in makeshift housing to be close to their lease, and to protect it from either being mined by others or being robbed. A number of the women interviewed indicated that the time they had to spend mining impacted negatively on the time they could spend with their children, and on other home-related issues. Most reported that despite their concerns, financially they had no choice but to continue mining as they needed to have money to support their households. Some of the women interviewed indicated that the men would go away to sell the gold and often waste the money on alcohol and prostitutes. Of the women who had been able to give up mining or reduce their time spent mining, health and safety concerns were cited as the main reason for their decision. 


\section{A possible way forward}

Women involved in ASM operations face huge socio-economic issues. The women indicated that accidents, injuries or lack of family support often forced them into mining operations. Without adequate knowledge of good safety and health practices, these women face work-related risks, forcing them into actions that by western standards would be viewed as unsafe and unacceptable. While in some areas few women are involved in mining, in other areas several generations may be seen mining together, including children, mothers, aunts and grandmothers. Safety records remain negligible, and as a result awareness of occupational health issues and prevention of accidents remains minimal. Women in these communities face competing responsibilities, including child rearing, domestic duties and subsistence farming, and often need to take their children with them to the mine site where they too are then exposed to health and safety issues associated with mining activity. However, recent figures have shown a positive trend indicating the number of school-age children on mine sites has reduced from approximately 30 per cent in 2005 to around 15 per cent, largely due to extensive awareness campaigns across the country highlighting the need for education opportunities to be maximised. Women do not have as many opportunities to acquire mining skills as their male counterparts, and so do not have equal access to the cash made through mining, despite playing an active role in the mining process. Education opportunities for women and girls in the mining areas are essential to their futures - many of the women interviewed lacked basic literacy stills. Essentially, the women lack access to information, microcredit and training.

Time is the most significant issue impeding these women from accessing opportunities to improve their livelihoods. The second-most significant issue for these women is their lack of literacy. The women who formed the discussion groups indicated that they could not attend training programs because the programs currently offered did not take into consideration their need to fulfil family and domestic obligations first and foremost, meaning they were not able to attend full-day or longer live-in programs. Thus, some issues to consider when developing training programs for women in remote mining communities are:

- Time constraints: the women are time poor, so delivery methods need to be flexible, sensitive and accommodating of their domestic and family obligations. 
- High rates of illiteracy and lack of basic education (this needs to be incorporated into all training programs).

- Women stereotyped as not being technically savvy.

- Traditional cultural beliefs and values precluding them from certain mining activities, meaning they often miss out on the benefit streams that naturally flow to the men.

- Lack of business/financial management skills.

- Lack of understanding of health and safety issues: mercury dangers, ground stability, mining methods, GBV, child labour, HIV/AIDS, water-borne diseases.

- Lack of access to microcredit.

Most importantly, training programs must be seen by the women to:

- Add value to their daily life and livelihoods.

- Must lead to activities that are practical, tangible and sustainable, and designed specifically for the users.

- Build capacity and empower the women.

- Not expose them to higher levels of GBV.

The women in the interview groups expressed a desire for information on safer working practices to enable them to understand what was safe and what was not. However, their health and safety concerns extend beyond work-related illnesses, to other issues that impact their families and communities. In particular, the women wanted training related to:

- Access to simple machinery and the technical knowledge of how to operate and maintain it.

- Safer and less physical mining practices.

- Understanding the hazards associated with mining practices, and how to undertake safer mining practices.

- Understanding how to prevent injury to themselves and other family members engaged in mining.

All of the women interviewed expressed health and safety concerns, with many expressing the opinion that it was their responsibility to ensure the health and safety of their families, including male members of their family having a good understanding of safe working practices. While some of the women expressed a desire for an alternative source of income, for many of those interviewed mining was the only occupation they had generational 
experience in, and they wanted to remain miners, not wanting to re-skill as farmers or service providers. All indicated they would value a means of obtaining knowledge and information to help them understand and manage the health and safety issues they saw as major concerns influencing their family's welfare.

In 2005, the Assistant Director of the Small-Scale Mining Branch of the Department of Mines, PNG, contended that the fundamental safety issue in SSM in PNG was that most miners lacked knowledge and skills on health and safety issues. This lack of knowledge translated to the inability to identify hazards and underestimation of the risk of being injured or killed, as the primary goal was to access high-grade gold for economic survival. It would seem that 10 years on this still remains a significant challenge for the Small-Scale Mining Branch of the MRA. At the Alluvial Mining Congress in Lae, PNG, held on 29-30 September 2015, representatives from the MRA-managed SSMTC highlighted some of the health and safety issues associated with alluvial and small-scale mining, and the difficulties in reaching small-scale miners with training. Operating since 2009, the centre conducts live-in two-week courses covering a number of mining-related subjects, including occupational health and safety, and outreach training programs across many remote alluvial mining areas of PNG, including adjacent islands. A significant challenge for the centre is the low literacy level of alluvial and small-scale miners attending the courses. Courses are developed and conducted at three levels: illiterate, semi-literate and educated. Despite having a high practical component, financial constraints make it difficult to attract attendees. By 2015, the centre had trained over 4,500 alluvial and small-scale miners; however, trainers estimate over 90,000 miners remain untrained. While courses are available to both male and female participants, the programs are delivered either in a two-week training block requiring participants to live at the facility, or as a one-week outreach program. While all women interviewed expressed genuine concern at their lack of health and safety knowledge, all indicated that family responsibilities generally preclude them from attending formal training programs that require extensive time commitments. Women in general tend to stay away from outreach programs for miners.

In order to provide effective training programs, it is necessary to accurately document target audience concerns, and provide training for local people in their local language. When asked what kind of program would work best for them, the women indicated a preference for flexible and informal training programs lasting two to three hours per day over three days of 
the week. The program would need to incorporate a level of basic literacy training for the women. Development of a program such as this would have widespread application, not only to other communities in PNG, but also to other countries where women are engaged in ASM activities.

\section{Conclusion}

Health and safety issues are inextricably linked to community, economic and environmental aspects of SSM. Despite the significant health and safety issues related to small-scale mining, alluvial gold-mining remains attractive in PNG, as miners can receive up to 70-90 per cent of market value, compared to rural commodities, which are paid at a much lower rate and generally take longer to realise any financial return. While women's participation is estimated at around 30 per cent, men and women are differently impacted upon by mining practices, cultural practices and legislative practices. The interviews provided a rich and valuable source of gender-specific information on SSM-related health and safety issues, which have not been well documented to date.

These interviews provided valuable insight and information that will assist the development of targeted training programs to help women better understand and manage health and safety issues that affect them and their families, and are consequently a step forward to improving their overall quality of life.

\section{Acknowledgements}

The writer acknowledges the assistance of the Minerals Resources Authority (MRA) and the Small-Scale Mining Training Centre (SSMTC) located at Wau Province, and in particular the assistance of the Centre Manager Al B. Comparativo, Business Manager Otto Morabo, trainer Immaculate Javia and the mining women of Wau who participated in the interviews.

\section{References}

Aubynn, T., 2009. 'On Mainstreaming ASM Research Findings.' Paper presented to Ghana Chamber of Mines, Accra Ghana, 16 September. 
Buxton, A., 2013. 'Responding to the Challenge of Artisanal and SmallScale Mining: How Can Knowledge Networks Help?' London: International Institute for Environment and Development.

Crispin, G., 2003. 'Environmental Management in Small-Scale Mining in PNG.' Journal of Cleaner Production 11(2): 175-83. doi.org/ 10.1016/S0959-6526(02)00037-9

Crispin, G., 2006. 'Women in Small-Scale Gold Mining in Papua New Guinea.' In K. Lahiri-Dutt and M. Macintyre (eds), Women Miners in Developing Countries: Pit Women and Others. Aldershot: Ashgate.

Eftimie, A., K. Heller, J. Strongman, J. Hinton, K. Lahiri-Dutt, N. Mutemeri, C. Insouvanh, M. Godet Sambo and S. Wagner, 2012. Gender Dimensions of Artisanal and Small-Scale Mining: A Rapid Assessment Tool. Washington, DC: World Bank Group's Oil, Gas and Mining Unit. Available at siteresources.worldbank.org/ INTEXTINDWOM/Resources/Gender_and_ASM_Toolkit.pdf

Gratz, T., 2003. 'Gold-Mining and Risk Management: A Case Study from Northern Benin.' Ethnos: Journal of Anthropology 68(2): 192208. doi.org/10.1080/0014184032000097740

Hancock, G., 1994. 'The Economics of Small-Scale Mining in Papua New Guinea.' In A.K. Ghose (ed.), Small-Scale Mining: A Global Overview. Rotterdam: A.A. Balkema.

Hayes, K., 2008. 'Artisanal \& Small-Scale Mining and Livelihoods in Africa.' Amsterdam: Common Fund for Commodities.

Heemskerk, M., 2003. 'Self-Employment and Poverty Alleviation: Women's Work in Artisanal Gold Mines.' Human Organization 62(1): 62-73. doi.org/10.17730/humo.62.1.5pv74nj41xldexd8

Hentschel, T., F. Hruschka and M. Priester, 2002. Global Report on Artisanal \& Small-Scale Mining. Minerals Mining and Sustainable Development, no. 70. International Institute for Environment and Development, World Business Council for Sustainable Development.

Hilson, G., 2002. 'Small-Scale Mining and its Socio-economic Impact in Developing Countries.' Natural Resources Forum 26: 3-13. doi. org/10.1111/1477-8947.00002 
Hilson, G. and J. McQuilken, 2014. 'Four Decades of Support for Artisanal and Small-Scale Mining in Sub-Sahara Africa: A Critical Review.' Extractive Industries and Society 1(1): 104-18. doi.org/10.1016/j. exis.2014.01.002

Hinton, J.J., M.M. Veiga and C. Beinhoff, 2003. 'Women and Artisanal Mining: Gender Roles and the Road Ahead.' In G. Hilson (ed.), The Socio-Economic Impacts of Artisanal and Small-Scale Mining in Developing Countries. The Netherlands: Swets \& Zeitlinger B.V. Publishers. doi.org/10.1201/9780203971284.ch1 1

Javia, I. and P. Siop, 2010. 'Paper on Challenges and Achievements on Small Scale Mining and Gender: Papua New Guinea.' Paper presented at Women in Mining Conference SIDS-18. New York, 10 May.

Jenkins, K., 2014. 'Women, Mining and Development: An Emerging Research Agenda.' Extractive Industry and Society 1(2): 329-39. doi. org/10.1016/j.exis.2014.08.004

Jennings, N., 1999. 'Social and Labour Issues in Small-Scale Mines.' Report for discussion at the Tripartite Meeting on Social and Labour Issues in Small-Scale Mines. Geneva, Switzerland: International Labour Organization.

Jennings, N., 2003. 'Addressing Labour and Social Issues in Small-Scale Mining.' In G. Hilson (ed.), The Socio-economic Impacts of Artisanal and Small-Scale Mining in Developing Countries. The Netherlands: Swets \& Zeitlinger B.V. Publishers. doi.org/10.1201/9780203971284.ch10

Krimbu, J., 2005. 'Gender Issues in Small-Scale Mining.' Paper presented at a workshop on Community and Small-Scale Mining: Sharing Experiences from the Asia-Pacific Region held in Manila, Philippines, 7-12 June. Viewed at www.casmite.org (site discontinued)

Lahiri-Dutt, K., 2006. 'Globalization and Women's Work in the Mine Pits of East Kalimantan, Indonesia.' In K. Lahiri-Dutt and M. MacIntyre (eds), Women Miners in Developing Countries: Pit Women and Others. Aldershot: Ashgate.

Lahiri-Dutt, K., 2008. 'Digging to Survive: Women's Livelihoods in South Asia's Small Mines and Quarries.' South Asian Survey 15(2): 217-44. doi.org/10.1177/097152310801500204 
Lahiri-Dutt, K., 2012. 'Digging Women: Towards a New Agenda for Feminist Critiques of Mining.' Gender Place and Culture 19(2): 193-212. doi.org/10.1080/0966369X.2011.572433

Leonhard, S., 2015. 'MRA Small-Scale Mining Training Centre.' Paper presented at the 2nd PNG Alluvial Mining Convention, Lae, PNG, 29-30 September.

Lole, H., 2005. 'The Trend in Artisanal and Small-Scale Mining Development in Papua New Guinea.' Paper presented at a workshop on Community and State Interests in Small-Scale Mining: Sharing Experiences from the Asia-Pacific Region, Manila, Philippines, 7-12 June.

Lopez-Trueba, M., 2014. "'Looking at Risk with Both Eyes": Health and Safety in the Cerro Rico of Potosí (Bolivia).' University of Sussex (PhD thesis). Available at sro.sussex.ac.uk/51385

Macintyre, M., 2006. 'Women Working in the Mining Industry in Papua New Guinea: A Case Study from Lihir.' In K. Lahiri-Dutt and M. Macintyre (eds), Women Miners in Developing Countries: Pit Women and Others. Aldershot: Ashgate.

Minerals Commission Ghana, 2014. Report of the Performance of the Mining Industry (2014). Viewed at www.ghanachamberofmines.org/ media/publications/Performance_of_the_Mining_Industry_Ghana _2014 (site discontinued)

Minerals Resources Authority, 2015. 'Corporate Plan, 2008-2013.' Viewed at www.mra.gov.pg/Portals/2/Publications/MRA\%20Plan \%20-\%202008\%202013.pdf (site discontinued)

Moramo, O., 2015. 'Small-Scale Alluvial Mining.' Paper presented at the 2nd PNG Alluvial Mining Convention, Lae, PNG, 29-30 September.

Moretti, D., 2005. 'Community and State Interests in Small-Scale Mining.' Paper presented at a workshop on Community and State Interests in Small-Scale Mining: Sharing Experiences from the AsiaPacific Region, Manila, Philippines, 7-12 June.

Moretti, D., 2006. 'The Gender of the Gold: An Ethnographic and Historical Account of Women's Involvement in Artisanal and SmallScale Mining in Mount Kaindi, Papua New Guinea.' Oceania 76(2): 133-49. doi.org/10.1002/j.1834-4461.2006.tb03041.x 
Moretti, D., 2007. 'Report on the Japan Social Development Fund Project on Artisanal and Small-Scale Mining in Papua New Guinea.' Research report, Artisanal and Small-Scale Mining in Asia-Pacific Case Studies Series. Viewed at www.asmasiapacific.org (site discontinued)

Papua New Guinea Mine Watch, 2015a. 'ABG Not Doing Enough Awareness on Potential Dangers of Alluvial Mining.' Available at ramumine.wordpress.com/tag/alluvial-mining

Papua New Guinea Mine Watch, 2015b. 'Alluvial Mining a Sleeping Giant.' Available at ramumine.wordpress.com/tag/alluvial-mining/

Simatauw, M., 2009. 'The Polarisation of the People and the State on the Interests of the Political Economy and Women's Struggle to Defend their Existence: A Critique of Mining Policy in Indonesia.' In I. Macdonald and C. Rowland (eds), Tunnel Vision: Women and Communities. Fitzroy, Victoria: Oxfam Community Aid Abroad.

Susapu, B. and G. Crispin, 2001. 'Report on Small-Scale Mining in Papua New Guinea.' London: International Institute for Environment and Development.

Tschakert, P., 2009. 'Recognising and Nurturing Artisanal Mining as a Viable Livelihood.' Resource Policy 34(1/2): 24-31. doi. org/10.1016/j.resourpol.2008.05.007

Van Hoecke, E., 2006. 'The Invisible Work of Women in the Small Mines of Bolivia.' In K. Lahiri-Dutt and M. Macintyre (eds), Women Miners in Developing Countries: Pit Women and Others. Aldershot: Ashgate.

Veiga, M.M. and R. Baker, 2004. 'Protocols for Environmental and Health Assessment of Mercury Released by Artisanal and Small-Scale Gold Miners.' Report to the Global Mercury Project. Vienna: United Nations Industrial Development Organization.

World Health Organization (WHO), n.d-a. 'Constitution of WHO: Principles.' Available at www.who.int/about/mission/en/

World Health Organization (WHO), n.d-b. 'Occupational health.' Available at www.who.int/topics/occupational_health/en/

World Health Organization (WHO), 2013. 'Mercury and Health Factsheet.' Available at www.who.int/mediacentre/factsheets/fs361/ en/ 
This text is taken from Between the Plough and the Pick: Informal, artisanal and small-scale mining in the contemporary world, edited by Kuntala Lahiri-Dutt, published 2018 by ANU Press, The Australian National University, Canberra, Australia.

doi.org/10.22459/BPP.03.2018.07 